\title{
Setting up an assertive community treatment service
}

\author{
Andrew Kent \& Tom Burns
}

The last 20 years have witnessed a surge of interest in assertive community treatment (ACT) for the severely mentally ill (Drake \& Burns, 1995). ACT aims to help people who would otherwise be in and out of hospital on a 'revolving door' basis live in the community and enjoy the best possible quality of life. Services based on the ACT model seek to replace the total support of the hospital with comprehensive, intensive and flexible support in the community, delivered by an individual key worker or core services team. They are organised in a way that optimises continuity of care across different functional areas and across time.

ACT has been most extensively deployed in the United States, where various developments have culminated in the Programs in Assertive Community Treatment (PACT) model. The origins of PACT lie with the innovative and highly successful Training in Community Living (TCL) programme developed during the 1970s at the Mendota Mental Health Institute in Madison, Wisconsin (Marx et al, 1973). The TCL programme sprang from a recognition that contemporaneous community treatments did little more than maintain the chronically disabled patient in "a tenuous community adjustment on the brink of rehospitalisation" (Stein \& Test, 1980).

The concepts underpinning TCL were simple, yet revolutionary. Its architects, Arnold Marx, Leonard Stein and Mary Ann Test, realised that an effective community treatment programme must assume responsibility for helping the patient meet all of his or her needs. They argued that these needs include the material essentials of life, such as food, clothing and shelter; coping skills necessary to meet the demands of community living; motivation to persevere in the face of life's adversity; freedom from pathologically dependent relationships, and support and education of significant others involved with the patient in the community.

The expectation that the socially disabled patient would come to the clinician was replaced with the expectation that the clinician would be assertive in delivering care and go to the patient. The assumption that the patient would negotiate the difficult pathways between different caring agencies was replaced with the assumption that the clinician is responsible for ensuring coordination of interagency care. The role of the key worker became preeminent, assuming responsibility for delivering a greater proportion of direct care to a much smaller number of allocated patients. Care became needsled, and care programmes were designed for each individual patient.

The results of Stein \& Test's original, randomised, controlled study of TCL retain their power to impress. Over the first year of the programme, 58\% of the patients randomised to progressive, standard care were readmitted to a psychiatric hospital compared with $6 \%$ of patients receiving TCL. Not only were patients on the TCL programme more likely to live independently in the community, but their clinical state improved, together with their social functioning, likelihood of employment, compliance with medication and, most important of all, their quality of life. These gains were achieved without additional burden on families or other informal carers, and (despite the intensity of intervention) at no extra cost because of the saving on beds (Test \& Stein, 1980; Weisbrod et al, 1980). These results have been interpreted to suggest that TCL was significantly less expensive than standard, progressive care. When funding for the programme was withdrawn, all of the gains were lost. Assertive community treatment needs to be offered to patients over the longer term.

Andy Kent is a Senior Lecturer in Community Psychiatry at St George's Hospital Medical School. Tom Burns is Head of the Section of Community Psychiatry at St George's. They are participating in a large multi-centre trial of intensive case management. Professor Burns has established an Assertive Community Treatment service in Wandsworth. 
The enormous influence of the TCL model can be attributed to the rigour with which the original programme was evaluated. Many other studies have followed (Olfson, 1990; Burns \& Santos, 1995). One of the most influential of these was an early replication of the TCL model in Sydney, Australia (Hoult $e t$ al, 1983). To date there have been over 20 randomised controlled trials of ACT, making it the most extensively researched service development in community psychiatry. In spite of this, we still do not know exactly which components of ACT are critical for outcome.

In Britain, the largest study of an assertive community treatment to date is of the Daily Living Programme (DLP; Marks et al, 1994). The results of this were a significant reduction in duration of hospitalisation, although not its frequency. There were some modest clinical gains at 18 months and considerable benefits in terms of patient satisfaction. Like TCL, the DLP demonstrated a rapid loss of gains when the service was withdrawn. Unlike Stein \& Test, however, the investigators found no financial advantage - probably because of the major start-up costs of the scheme and a focus on a more acutely ill patient group. The study was also compromised by a number of extraneous factors a highly publicised homicide and shifts in clinical control of in-patient services.

\section{The key elements of ACT}

The TCL/PACT approach has been very well described (Test, 1992). A multidisciplinary core services team (continuous treatment team) is responsible for helping its patients meet all of their needs, and does so by being the primary provider of relevant services wherever possible. The team offers continuity of care over time and across traditional service boundaries 24 hours a day, seven days a week. Patients are engaged and followed up assertively, and treatment is offered in the community rather than at traditional service settings. The emphasis is on helping patients function as independently as possible, by teaching and enhancing skills in the environment where they will be needed, rather than in day hospitals and sheltered workshops. The patient is assisted in meeting basic needs, such as housing, food and work, and the development of a supportive social and family environment. Care plans for each patient are individualised and adaptable to changing needs over time. Goals, such as reduced symptom severity, increased community tenure and improved instrumental functioning, are explicit. A key worker from the team is responsible
Box 1. Key elements of the PACT model (adapted from Test, 1992)

A core services team is responsible for helping the patient meet all of his needs and provides the bulk of clinical care

Improved patient functioning (in employment, social relations and activities of daily living) is a primary goal

The patient is directly assisted in symptom management

One team member acts as a patient's key worker and coordinates all of the patient's care

Individual key workers have small case loads (10-15 patients)

Treatment is individualised between patients and over time

Patients are engaged and followed up in an assertive manner

Treatment is provided in vivo, in community settings - skills learnt in the community can be better applied in the community

Care is continuous both over time and across functional areas

for providing and coordinating the care of each individual patient, and helps the patient manage his or her symptoms on a day-to-day basis, including overseeing medication (see Box 1).

ACT is therefore a pure form of clinical case management (Kanter, 1989) and lies at the opposite end of the case management continuum to the earlier 'brokerage' model (Thornicroft, 1991). Many of its underlying concepts have become emblematic of good clinical practice. Individualised, needs-led care planning coordinated by a key worker is the cornerstone of the Care Programme Approach (Department of Health, 1990).

A few authors have attempted to tease out those components of PACT which are critical for its success (McGrew et al, 1994; Teague et al, 1995). A better understanding of the critical components will facilitate precise application of the model in a greater variety of circumstances. Although there is widespread consensus on the likely components, prospective studies of programme fidelity are urgently required (Taube et al, 1990).

\section{What does an ACT team do?}

ACT has traditionally been delivered by discrete clinical teams operating alongside generic, locally 
based mental health services. An individual team member acts as an intensive case manager (ICM) to a small group of patients (no more than 15, and usually less than 12) to help each patient meet all of their needs. Before these needs can be identified, the key worker must engage the patient in a therapeutic relationship. It is difficult to overstate the importance, and all too often the difficulty, of this task. One of the obvious strengths of the ACT model is that key worker time is protected and available for such fundamental work.

The core task of engagement is to build and foster a positive attitude on the part of the patient to both the key worker and treatment. The process of engagement pervades many other tasks, but in its purest form involves general problem solving, joint recreational activity (for example, going to see a film together), and befriending. These are generally not activities afforded high status in mental health work, often being delegated to voluntary organisations. The need for the key worker to foster a close therapeutic relationship that in all probability will last for many years lends them a new, and appropriate, priority.

\section{Case 1.}

$\mathrm{NH}$ is a 53-year-old isolated Irish man with a 30 year history of schizophrenia who despite several admissions has always resisted follow-up. When he had been admitted to hospital, it was always in a severely neglected state, usually under a section of the Mental Health Act. His previous compliance with medication had been very poor and he had consistently refused follow-up from a community psychiatric nurse (CPN). His intensive case manager was initially subject to the same resistance. He noted amid the general squalor of $\mathrm{NH}^{\prime} \mathrm{s}$ small flat that the toilet did not flush and found out that it had not for over two years. NH had regularly filled a bucket of water to flush it. It took the case manager $\mathbf{4 0}$ minutes and $£ 3.60$ of petty cash to fix it. NH (who had previously insisted that he did not mind the problem) was clearly delighted, allowed the case manager to visit more regularly and start to take him shopping (an activity previously inhibited by a complex set of delusions). As a consequence, he began to eat a more adequate diet.

In the midst of this, he allows his medication to be monitored and has no great opposition to taking it. There remains much still to be done - he is still refusing to seek his benefits, get a check up from his GP or improve his hygiene. He has, however, remained in contact for $\mathbf{1 5}$ months, which for him is a record.

\section{Case 2.}

GH is a 32-year-old man of West African descent who has suffered from schizophrenia for 9 years, with a history of multiple admissions under the Mental Health Act. His family are concerned and support him when he is well, but are excluded when he deteriorates. Despite his severe disability, he regularly seeks open employment and becomes threatening and hostile when rejected. Previous follow-up has usually been restricted to depot phenothiazines and is often characterised by suspicion and rejection of his CPN.

In the early stages of engagement, he regularly 'sacked' his intensive case manager. The ICM found that if he went back a few days later and did not mention the 'sacking', it was not brought up by the patient. The ICM has found that periods of resistance and hostility are best managed simply by changing the focus of the interview, and this is possible because they are engaged in a number of ventures - redecorating the flat and pursuing a place on a motor mechanic training course. Medication has been maintained for over one year and regular family meetings have helped the patient's mother to understand his illness better. She has successfully adopted some of the conflict avoidance techniques she has seen the case manager use.

At an early stage, the ICM works collaboratively with the patient to identify his or her needs. This process must be systematic, and may be facilitated by the use of a standard instrument such as the Camberwell Assessment of Need (Phelan et al, 1995). ICM activity with individual patients can be grouped in the following seven broad categories: help with housing, finance, medication, occupation and leisure, daily living skills, the criminal justice system and physical health. Clear and explicit goals, derived from identified needs, strengthen collaboration between ICM and patient on a dayto-day basis. For example, the task of getting up at a reasonable hour can be linked with the goal of getting a job and earning money. American ACT services place a high emphasis on occupational rehabilitation. The motivation to earn money and be identified with a more normal role in society can be harnessed to powerful effect by a key worker who has intensive contact (at least twice a week) with the patient over many years.

\section{Setting up a local ACT service}

\section{Establishing the local need}

Assertive community treatment has been shown to benefit those patients trying to live in the community who have the highest degree of social disablement. Such patients are not necessarily those who have the highest level of contact with community mental health teams (CMHTs); many actively avoid contact. Our own experience has also 
taught us that while CMHTs readily identify the small group of patients who require a disproportionate amount of care, they tend to overestimate the number of severely mentally ill patients with whom they have regular contact. This discrepancy reflects the absence of a consensus on the definition of severe mental illness. Diagnosis alone is clearly a poor indicator, but a rigidly formulaic approach to definition is impractical. We have found Bachrach's (1988) characterisation of this group most useful, using diagnosis, duration and disability.

\section{Team structure}

Assertive community treatment appears to work best when the ACT team has overall clinical responsibility for all aspects of patient care including in-patient care. The DLP study demonstrated the problems which may arise with divided consultant responsibility. The easiest, and arguably the neatest, system is for the ACT team to be selfcontained, retaining consultant medical responsibility for care of the patients at all times and exercising control over a small in-patient facility. There are potential problems with this approach in the UK, where over $80 \%$ of mental health services are sectorised (Johnson \& Thornicroft, 1993). The creation of additional teams may fragment the existing comprehensive service. There is a danger, too, of blunting the commitment of CMHTs to work with the severely mentally ill, by removing responsibility for the care of the most disabled. Our approach has been to integrate ACT key workers into existing CMHTs. In addition to avoiding service fragmentation, this model utilises existing patterns of vertical (primary-secondary-tertiary) and horizontal (health-local authority) service integration. A potential problem with this approach is the dilution of programme fidelity and diminished influence on in-patient care (see Table 1).

Surprisingly little is known about the ideal size of a mental health team in the UK (Onyett et al, 1994). We suggest a minimum of five intensive case managers to allow leave to be covered internally. More than eight begins to become unwieldy, making regular review, and familiarity of all case managers with all patients, difficult. ACT services in the US have successfully used both skilled mental health professionals and 'fresh' staff with non-vocational qualifications as case managers. Skilled staff with an accredited training in mental health work are significantly more expensive to employ, and many of the core tasks of ACT appear relatively straightforward and simple. Their skill, however, lies in achieving them with people who are profoundly disabled by severe mental illness

\begin{tabular}{|c|c|}
\hline Potential advantages & Potential disadvantages \\
\hline $\begin{array}{l}\text { Full multidisciplinary } \\
\text { support }\end{array}$ & $\begin{array}{l}\text { Loss of programme } \\
\text { fidelity }\end{array}$ \\
\hline $\begin{array}{l}\text { Vertical and horizontal } \\
\text { service integration }\end{array}$ & $\begin{array}{l}\text { Secondment of key } \\
\text { workers to other (non- } \\
\text { ACT) tasks }\end{array}$ \\
\hline $\begin{array}{l}\text { Avoids fragmentation } \\
\text { of sectorised community } \\
\text { mental health services }\end{array}$ & $\begin{array}{l}\text { Inefficient use of time } \\
\text { (e.g. multiple meetings) }\end{array}$ \\
\hline $\begin{array}{l}\text { Retains CMHT focus on } \\
\text { the severely mentally ill }\end{array}$ & Professional isolation \\
\hline Skill sharing & $\begin{array}{l}\text { Reduced control of } \\
\text { in-patient stays }\end{array}$ \\
\hline
\end{tabular}

and in maintaining a longer-term relationship. Fresh staff, on the other hand, may be unburdened by inappropriate professional attitudes, and better able to adapt to the role of intensive case manager. The arguments for and against the employment of highly skilled staff remain unresolved, although available evidence suggests that they may achieve better outcomes.

There is no evidence to indicate that any one group of mental health professionals is better equipped to act as case managers than any other. ACT is holistic in its attention to patients' needs, and case managers must adopt a generic approach, whatever their professional backgrounds. Nevertheless, in the absence of hard data it seems logical to recommend that ACT teams retain a multidisciplinary skill mix. Community psychiatric nurses (CPNs) have a particularly valuable role with respect to medication, and perhaps of all mental health professionals are the most skilled at promoting compliance with medication - an important vector of good outcome in ACT. Occupational therapists and social workers also have highly relevant skills, and if they can be recruited to the ACT team, this is to be particularly recommended. Clinical psychologists have been more prominent in some of the American ACT teams than they have in the UK. If it is not possible to recruit a psychologist to the team, then access to psychological skills outside the team is essential. We suggest that a team which mixes nurses and non-nurses in equal proportion is optimal.

\section{Team meetings}

In the US, most ACT teams meet briefly every day. A team should certainly meet at least twice a week. We suggest at least three times a week in the first year to build cohesiveness and strengthen the new 
professional identity. Each meeting should include hand-over information about all patients, and a review of two or three patients in-depth each week to update individual care programmes. Time needs to be devoted on a regular basis to professional development and discussion of the new and challenging role of being an intensive case manager.

\section{Cross cover}

Key workers should not just cover each other for holidays and absences. Patient involvement with other case managers is essential to avoid the development of pathological and over-dependent relationships. Individual case managers can then discuss their patients with colleagues who have first hand knowledge of them. Although the concept of 'team responsibility' for all patients has been advocated by some services (Witheridge, 1991; Haringey Mental Health Group, 1994), we see a major benefit in having a clearly identified individual responsible for the care of the patient. The likelihood of confusion is decreased, and the essential benefits of case management (i.e. a clear focus for the planning, coordination and delivery of care) protected. In our opinion, a team model undervalues the essential importance of the individual therapeutic relationship in supporting the patient.

\section{Extent of service}

Services adhering fully to the PACT model offer access to a key worker from the team 24 hours a day. It is not apparent, however, that there are substantial advantages to 24 hour access to an ACT service in the UK, where primary care and 'out of hours' emergency mental health services are highly developed and accessible. The tasks of case management are usually most efficiently conducted during 'office hours', when liaison with other key agencies (e.g. social services, housing, social security) is possible. As few of the patients using the service are employed, most will be able to meet with their key workers between 9 am and $5 \mathrm{pm}$. Key workers will, however, need to be regularly available outside of these times - particularly when engaging a patient, supporting leisure activities or working with carers. Our own review of the literature indicates that 24 hour services in the UK may add little to an 'extended hours' service at a considerably greater cost. We piloted an extended hours ACT service (until $10 \mathrm{pm}$ ) in our district and found it very little used, and have subsequently disbanded it.

\section{Supervision and leadership}

As we gain clearer understanding of the critical components of $\mathrm{ACT}$, the importance of programme fidelity is increasingly apparent. An ACT team needs to be led by someone with previous experience of the model, who can provide regular supervision and support to other key workers. Staff burnout has been perceived as a potential problem with $\mathrm{ACT}$, but intensive case managers typically report high job satisfaction. Nonetheless, long-term, intensive work with a small number of seriously ill patients brings its own unique stresses.

\section{Team model and operational policy}

Identifying a model and drawing up an operational policy should logically come first, but experience has taught us otherwise. Although a team model has to be identified before staff are recruited, the operational policy is best evolved and regularly reviewed with the team members themselves. This leads to a greater sense of ownership and commitment.

A well written operational policy will become an invaluable document which will both guide subsequent development and implementation of the service, and also serve as a reference once the service is up and running. It needs to be written in clear and simple language and should describe the definition, philosophy and aims of the service, together with operational details such as staff skill mix, training and deployment, together with a brief, operationalised definition of patients who will be accepted by the service and broad practice guidelines. The components of the PACT model identified in this paper could usefully be used as a starting point (see Box 2).

\section{Resistance and problems}

Setting up a new, innovative service may generate major resistance. This has been repeatedly reported by investigators of such services in the UK and needs to be approached philosophically. The source of resistance is both external and internal.

\section{External resistance}

The major external resistance is professional anxiety about change. The new service may be perceived as a threat to the position and status of 


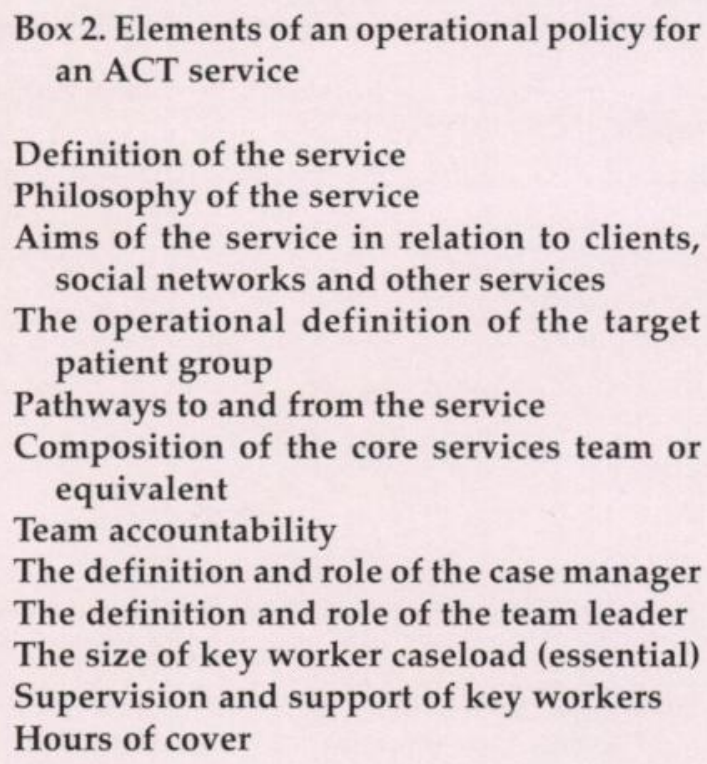

Box 2. Elements of an operational policy for an ACT service

\section{Definition of the service}

Philosophy of the service

Aims of the service in relation to clients, social networks and other services

The operational definition of the target patient group

Pathways to and from the service

Composition of the core services team or equivalent

Team accountability

The definition and role of the case manager

The definition and role of the team leader

The size of key worker caseload (essential)

Supervision and support of key workers

Hours of cover

the various mental health professions. We experienced initial resistance from psychiatry, nursing, clinical psychology and occupational therapy, and much later on from social work. Many psychiatrists felt that the proposal for a new assertive community treatment service described nothing new, and that intensive case management was already being provided as required by CMHTs. There was also a concern that the new service could lead to confusion regarding clinical responsibility for individual patients.

Community psychiatric nurses were worried that their jobs might be threatened. For occupational therapists and clinical psychologists it appeared that the high profile of a major service development which relied heavily on their skills, but which was not under their control, contributed. Resistance from social workers developed more slowly, reflecting their generally positive view of generic functioning. The clarity of definitions in such a service (e.g. patient characteristics, case load size, regularity of contact) is unusual in NHS mental health services and can be perceived as implied criticism of the imprecision that is traditionally accepted. For example, rigorously established case loads can highlight uncertainty about workloads and skill mixes elsewhere in the system. Tight control over such a service also evokes fears of a rigid 'medical model'.

\section{Internal resistance}

Within the new team there will be anxiety about the new key worker role, particularly with regard to tasks outside traditional professional boundaries. Concerns about over-dependency on the part of the patient partly derive from the increased level of self-disclosure that is inevitable in such an extended key worker role. The ethics of pursuing reluctant patients was regularly debated by members of our service. This is a real issue but often served as a platform for the expression of external resistance. There is a fine line between assertiveness and harassment. Such judgements have to be made in most clinical situations, but are particularly prominent in ACT services.

\section{Summary}

Our service is only in its second year and is subject to an extensive evaluation. Informed judgements about its value will have to await that analysis. Some early differences can, however, be observed. After an initial period of finding the new role difficult and feeling 'uncontained' case managers report high levels of job satisfaction from their limited case loads and extended remit. Keeping patients engaged has undoubtedly been improved by the new approach and the sense of freedom to do what is needed to make the patient feel better (rather than to focus too narrowly on 'illness issues') has resulted in an improved therapeutic alliance. Medication compliance may have improved because it is no longer such an issue - just one part of a complex and generally rewarding relationship. One gratifying result has been a markedly improved uptake of benefits by the patients and an overall impression of improved material conditions. The relationship between case managers and other disciplines has steadily improved. It has been helped along by shared experience of admissions of case manager clients and a recognition that this approach is not a 'cureall'. Nothing succeeds like failure.

In spite of all of the potential problems that may be encountered in setting up an assertive community treatment service, the benefits are considerable. Benefits to the patients include obvious improvement in quality of life, and for many, the avoidance of episodic crises resulting in major emotional and social upheaval. There are also benefits to other clients of the mental health service - as a consequence of the more efficient use of expensive inpatient services and the liberation of these resources for CMHTs.

The gap between the outcome for patients of ACT and standard community mental health services may continue to close as the latter adopt more of the principles of the former (Burns \& Santos, 1995). If so, then the pioneers of ACT have a great deal to be thanked for. There are certainly potential 
benefits for CMHTs in the UK in terms of new learning and new practice. Greater clarity and definition of target populations and openness about activities are attributes that all teams facing the demands and challenges of the 'new' NHS would be served by. Such clarity is rapidly developed in ACT teams.

\section{References}

Bachrach, L. L. (1988) Defining chronic mental illness: a concept paper. Hospital and Community Psychiatry, 39, 383-388.

Burns, B. J. \& Santos, A. B. (1995) Assertive community treatment: an update of randomised trials. Psychiatric Services, 46, 669-675.

Department of Health (1990) The Care Programme Approach for People with a Mental Illness Referred to the Specialist Psychiatric Services. (HC(90)23/LASSL(90)11). London: DoH.

Drake, R. E. \& Burns, B. J. (1995) Special section on assertive community treatment: an introduction. Psychiatric Services, $46,667-668$.

Haringey Mental Health Group (1994) Tulip. Annual Report 1993/1994. London: Haringey Mental Health Group.

Hoult, J., Reynolds, I., Charbonneau-Powis, M., et al (1983) Psychiatric hospital versus community treatment: the results of a randomised trial. Australian and New Zealand Journal of Psychiatry, 17, 160-167.

Johnson, S. \& Thornicroft, G. (1993) The sectorisation of psychiatric services in England and Wales. Social Psychiatry and Psychiatric Epidemiology, 28, 45-47.

Kanter, J. (1989) Clinical case management: definition, principles, components. Hospital and Community Psychiatry, 40, 361-368.

Marks, I. M., Connolly, J., Muijen, M., et al (1994) Home-based versus hospital based care for people with serious mental illness. British Journal of Psychiatry, 165, 179-194.

Marx, A. J., Test, M. A. \& Stein, L. I. (1973) Extrahospital management of severe mental illness. Archives of General Psychiatry, 29, 505-511.

McGrew, J. H., Bond, G. R. \& Dietzen, L. L. (1994) Measuring the fidelity of implementation of a mental health program model. Journal of Consulting and Clinical Psychology, 62, 670678.

Olfson, M. (1990) Assertive community treatment: an evaluation of the experimental evidence. Hospital and Community Psychiatry, 41, 634-641.

Onyett, S., Heppleston, T. \& Bushnell, D. (1994) The Organisation and Operation of Community Mental Health Teams in England: a National Survey. London: The Sainsbury Centre for Mental Health.

Phelan, M., Slade, M., Thornicroft, G., et al (1995) The Camberwell Assessment of Need: the validity and reliability of an instrument to assess the needs of people with severe mental illness. British Journal of Psychiatry, 167, 589-595.

Stein, L. I. \& Test, M. A. (1980) Alternative to mental hospital treatment. I. Conceptual model, treatment program and clinical evaluation. Archives of General Psychiatry, 37, 392-397.

Taube, C. A., Morlock, L., Burns, B. J., et al (1990) New directions in research on assertive community treatment. Psychiatric Services, 41, 643-647.

Teague, G. B., Drake, R. E. \& Ackerson, T. H. (1995) Evaluating use of continuous treatment teams for persons with mental illness and substance abuse. Psychiatric Services, 46, 689-695.

Test, M. A. (1992) Training in community living. In Handbook of Psychiatric Rehabilitation (ed. R. P. Liberman), pp. 153-170. New York: Macmillan.

- \& Stein, L. I. (1980) Alternative to mental hospital treatment. III. Social cost. Archives of General Psychiatry, 37, 409-412.

Thornicroft, G. (1991) Concept of case management for long-term mental illness. International Review of Psychiatry, 3, 125-132.
Weisbrod, B. A., Test, M. A. \& Stein, L. I. (1980) Alternative to mental hospital treatment. II. Economic benefit-cost analysis. Archives of General Psychiatry, 37, 400-405.

Witheridge, T. F. (1991) The 'active ingredients' of assertive outreach. In Psychiatric Outreach to the Mentally Ill (ed. N. L. Cohen), pp: 47-64. San Francisco: Jossey-Bass.

\section{Multiple choice questions}

1. Key elements of the PACT model include:

a Individualisation of treatment between patients and over time

b Patients are engaged and followed up assertively

c Key worker case loads vary from 15-20

d The avoidance of staff burnout by the regular reallocation of patients to keyworkers within the core services team.

2. The potential advantages of integrating ICMs into generic community health teams include:

a They have small case loads and so are able to help with the work of other team members at particularly busy times

b Responsibility for in-patient care is shared with staff who have experience of alternatives to the ACT approach

c Skills may be shared with other team members

d Fragmentation of existing services is avoided.

3. In general terms:

a There is no evidence to indicate that one group of mental health professionals is better equipped to act as ICMs than any other

b ACT teams function best of all if the ICMs are experienced community nurses

c Clinical psychologists are too highly trained to be employed as ICMs

d Individuals who lack a professionally accredited training in mental health work are unlikely to perform well as ICMs

e ICMs need to adopt a generic approach to patient care.

4. Assertive community treatment:

a Originated with the Daily Living Programme, in Madison in the 1970s

b Aims to replace the total support of the hospital with comprehensive support in the community

c Is more expensive than alternative forms of community care

d Optimises continuity of care across different functional areas and time. 
5. Compared to standard psychiatric care in the community, the training in Community Living Programme developed by Stein \& Test helped patients to:

a Live independently

b Obtain employment

c Stop medication without relapse

d Comply with medication.

\begin{tabular}{|c|c|c|c|c|c|}
\hline \multicolumn{6}{|c|}{ MCQ answers } \\
\hline 1 & 2 & 3 & & 4 & 5 \\
\hline a $T$ & a $\mathrm{F}$ & & $\mathbf{T}$ & a $F$ & a $\mathrm{T}$ \\
\hline b $\mathrm{T}$ & b $\mathbf{F}$ & b & F & b $\mathbf{T}$ & b $\mathrm{T}$ \\
\hline c $F$ & c 1 & & F & c $F$ & c $\mathrm{F}$ \\
\hline d F & d 1 & d & $\mathbf{F}$ & d $T$ & d $\mathrm{T}$ \\
\hline e $\mathrm{T}$ & & & $\mathbf{T}$ & & \\
\hline
\end{tabular}

\section{Commentary}

\section{Steven R. Hirsch}

It is difficult not to be won over by the description of assertive community treatment that promises nearly total caring for the most chronically disabled mentally ill, including "the material essentials of life such as food, clothing and shelter, coping skills necessary to meet the demands of community living and motivation to persevere in the face of life's adversity". If we keep in mind that this approach is for patients who in previous decades would have spent their life in a mental institution, one can readily justify the transfer of expense and resources to this hopefully more humane form of treatment which allows patients to live within the context of open society, a preference they inevitably opt for when surveyed after a move from hospitalisation to community care.

Unfortunately there are serious questions as to what extent this model can meet the shortcomings of community care in modern Britain. Even 15 years after the Stein \& Test (1980) original article there does not seem to be a description in the literature of any service which has been tested over a sustained period, say 5 years. The authors of this article, are only in their second year of providing such a service and they report that the Stein \& Test service, and Hoult's service in Australia were both closed down with a loss of patients' previous benefits. Nor is it clear to me whether the division between Social Security, Social Services, Housing and Health in the UK allow for the type of total combined approach which ACT seems to require. Care management should offer such an opportunity by providing a single total budget for patients selected for such treatment so perhaps this should be combined with ACT.

It would appear that ACT should improve the quality of life and level of functioning of some patients with chronic mental illness. There is a problem in identifying which patients should receive this type of care as opposed to alternative approaches, such as the provision of a haven of supervised residential homes for patients who cannot function even when offered ACT. There are also the groups who are violent, abuse drugs, or remain resistant to assertive outreach because of their own peculiar psychopathology. These limitations should be given recognition by advocates of any single approach so that a comprehensive mental health system can be provided to replace institutional care of the past.

Purchasers and providers should keep a reasonable balance between the resources invested into the most severe mentally ill and the resources required by the rest of the population, so that they too can have decent and respectable facilities when they require acute treatment in hospital, and have access to psychologists, psychiatrists and community psychiatric nurses even when they do not fall into the most severely disabled group. Advocates for mental health services should approach assertive community treatment with some caution until knowledge of the cost and benefits and the ability to sustain such a service on a long-term basis has been well established. 